\title{
Combined Effects of Benidipine and Diltiazem in a Rat Model of Experimental Angina
}

\author{
Kozo $\mathrm{Yao}^{1, *}$ and Shiro Shirakura ${ }^{1}$ \\ ${ }^{1}$ Biomedical Research Laboratories, Pharmaceutical Research Institute, Kyowa Hakko Kogyo Co., Ltd., \\ 1188 Shimotogari, Nagaizumi-cho, Sunto-gun, Shizuoka 411-8731, Japan
}

Received November 19, 2003; Accepted April 26, 2004

\begin{abstract}
We examined the combined effects of the calcium channel blockers 1,4-dihydropyridine (benidipine) and benzothiazepine (diltiazem) on vasopressin-induced myocardial ischemia in anesthetized rats, an experimental model of angina. Benidipine $(3,10 \mu \mathrm{g} / \mathrm{kg}$, i.v. $)$ and diltiazem $(300,1000 \mu \mathrm{g} / \mathrm{kg}$, i.v.) caused dose-related inhibition of vasopressin-induced S-wave depression, an index of myocardial ischemia. Co-administration of low doses of benidipine $(3 \mu \mathrm{g} / \mathrm{kg})$ and diltiazem $(300 \mu \mathrm{g} / \mathrm{kg})$ almost completely inhibited the S-wave depression, where the efficacy was similar to that obtained with the use of high doses of benidipine $(10 \mu \mathrm{g} / \mathrm{kg})$ or diltiazem $(1000 \mu \mathrm{g} / \mathrm{kg})$. These results suggest that the administration strategy employed may be useful in the treatment of angina pectoris.
\end{abstract}

Keywords: diltiazem, benidipine, angina

Several lines of evidence have indicated that calcium channel blockers are effective in the treatment of angina pectoris. Benidipine is a 1,4-dihydropyridine calcium channel blocker possessing slow-onset and long-lasting vasodilating effects and is clinically useful in the treatment of hypertension and angina pectoris (1). Karasawa et al. (2) have reported that benidipine has beneficial effects on various experimental angina models, including an arginine vasopressin (AVP)induced angina model.

In the treatment of angina pectoris, monotherapy using antianginal drugs is generally not completely effective for all types of angina pectoris (3). Combination therapy employing different types of agents has been used in an effort to improve on the clinical benefits of monotherapy. In fact, some clinical studies have demonstrated that the combined use of nifedipine and diltiazem was favorable in patients with angina pectoris $(4-6)$. In an effort to evaluate the effectiveness of combination therapy, the present study employed the use of two different types of calcium channel blockers, benidipine and diltiazem. Antianginal effects pertaining to AVP-induced angina were evaluated and compared to the therapeutic efficacy obtained with the use of either

*Corresponding author. FAX: +81-55-986-7430

E-mail: kozo.yao@kyowa.co.jp drug alone.

Male Donryu rats (9-11-week-old; Japan SLC, Shizuoka) were used in this study. Rats were kept at $23 \pm 1{ }^{\circ} \mathrm{C}$ under a 12 -h light-dark cycle, where they had free access to tap water and commercial chow (FR-2; Funabashi Farms, Chiba). All animals received humane care in compliance with the "Guiding Principles for the Care and Use of Laboratory Animals" formulated by The Japanese Pharmacological Society, and the protocol was approved by the Bioethical Committee of the Pharmaceutical Research Institute, Kyowa Hakko Kogyo Co., Ltd.

Benidipine (hydrochloride) was synthesized at Kyowa Hakko Kogyo (Tokyo). Diltiazem (hydrochloride) and AVP were purchased from Sigma (St. Louis, MO, USA). Benidipine and diltiazem were dissolved in physiological saline containing 0.1 vol $\%$ Tween 80 (Wako Pure Chemical, Osaka). Drug concentrations were adjusted to yield an injection volume of $0.1 \mathrm{~mL}$ $/ 100 \mathrm{~g}$ of body weight. The doses of benidipine and diltiazem were selected based on the study by Karasawa et al. (2). AVP was diluted with physiological saline to a concentration of $1 \mathrm{IU} / \mathrm{mL}$ solution.

The antianginal effects of the drugs were assessed according to the method of Hirata et al. (7). Rats were anesthetized with sodium pentobarbital $(60 \mathrm{mg} / \mathrm{kg}$, i.p.). 
The standard limb lead II electrocardiogram (ECG) was recorded to measure S-wave depression. The rats were allocated to the following 6 groups: vehicle $(n=12)$; benidipine, $3 \mu \mathrm{g} / \mathrm{kg} \quad(\mathrm{n}=8)$; benidipine, $10 \mu \mathrm{g} / \mathrm{kg}$ $(\mathrm{n}=8) ; \quad$ diltiazem, $300 \mu \mathrm{g} / \mathrm{kg} \quad(\mathrm{n}=8) ; \quad$ diltiazem, $1000 \mu \mathrm{g} / \mathrm{kg} \quad(\mathrm{n}=8)$; benidipine, $3 \mu \mathrm{g} / \mathrm{kg}+$ diltiazem, $300 \mu \mathrm{g} / \mathrm{kg}(\mathrm{n}=8)$. The test drugs were intravenously injected 5 min prior to the injection of AVP. AVP $(1 \mathrm{IU} / \mathrm{kg})$ was injected into the jugular vein, and ECG changes were recorded for the first $10 \mathrm{~min}$ following AVP injection. In a separate experiment, the effects of vehicle, benidipine at $3 \mu \mathrm{g} / \mathrm{kg}$, diltiazem at $300 \mu \mathrm{g} / \mathrm{kg}$, and their combination on blood pressure and heart rate were measured in normal anesthetized rats (each group consisted of 5 animals). The blood pressure was recorded on a polygraph through a blood pressure transducer connected to a cannula inserted into the carotid artery, and heart rate was measured by the blood pressure pulse wave. After each drug was intravenously administered, the changes of the blood pressure and heart rate were measured for $15 \mathrm{~min}$.

All values are expressed as means \pm S.E.M. All statistical calculations were performed using a computer and statistical analysis software (SAS, version 6.12; SAS Institute, Inc., Cary, NC, USA). Statistical analysis of the S-wave was performed using Student's $t$ - or the Aspin-Welch-test for comparison between two groups or using the Kruskal-Wallis test followed by the Steel's test for multiple comparison. Intergroup comparisons of blood pressure and heart rate between the vehicle

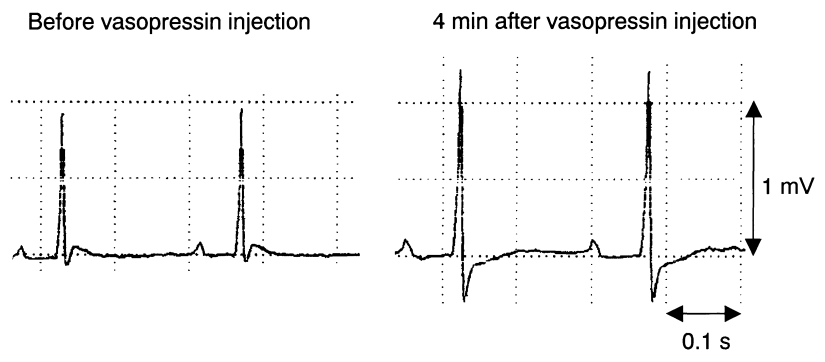

Fig. 1. Typical tracings of electrocardiogram (lead II) of anesthetized rats following intravenous injection of vasopressin.

administration group and the test drug administration groups at each time point were made by nested variance analysis, and then significant differences were tested by Student's $t$-test. A difference was considered to be statistically significant at $P<0.05$.

AVP is an antidiuretic hormone and a vasoconstrictor, where AVP produces vasoconstriction of small coronary arteries and increases total coronary resistance (8). The AVP-induced angina model is considered useful in evaluating antispasmodic effects of drugs in vivo $(2,7$, 9 - 11). When AVP was injected in the rats, a depression of the S-wave in the lead II ECG appeared $10 \mathrm{~min}$ following AVP challenge (Fig. 1), suggesting subendocardial artery ischemia occlusion of a major artery, with collaterals from an uninvolved artery (12). Changes in ST-segment were used as an index of ischemic severity. According to the previous report (2), the fall of
1) Benidipine

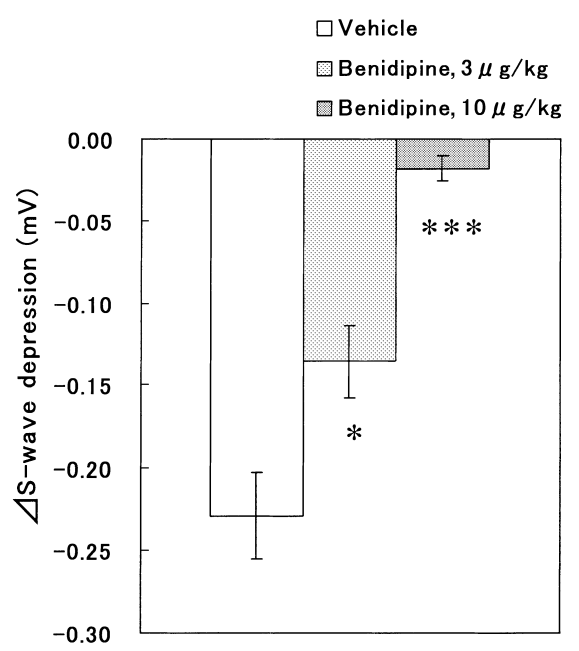

2) Diltiazem

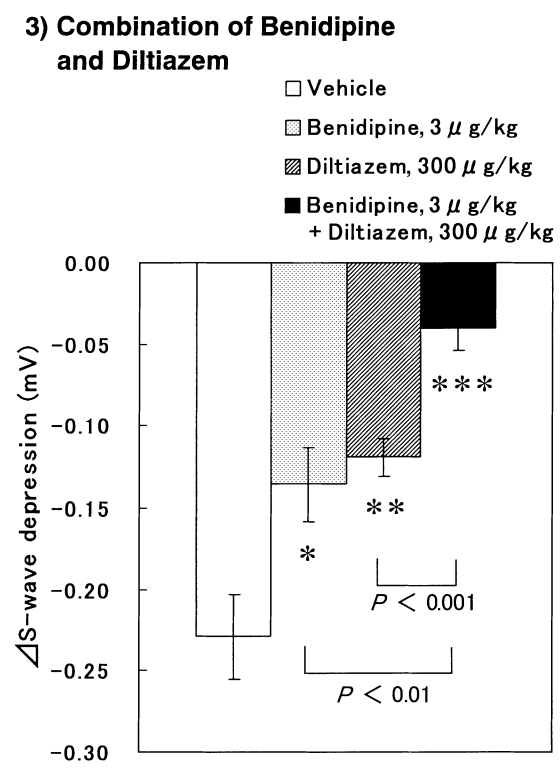

Fig. 2. Effects of benidipine (1), diltiazem (2), and their combination (3) on the maximum changes in vasopressin-induced S-wave depression in the electrocardiogram (lead II) in anesthetized rats. Drugs were administered intravenously 5 min prior to the vasopressin injection. Columns are means \pm S.E.M. of $8-12$ rats. ${ }^{*} P<0.05,{ }^{*} P<0.01,{ }^{* * *} P<0.001$ vs vehicle. 
S-wave was regarded as the fall of ST. Maximal S-wave depression was observed 4-5 min following AVP injection, consistent with previous reports $(10,11)$. Both benidipine ( 3 and $10 \mu \mathrm{g} / \mathrm{kg}$ ) and diltiazem (300 and $1000 \mu \mathrm{g} / \mathrm{kg}$ ) significantly inhibited the $\mathrm{S}$-wave depression in a dose-dependent manner (Fig. 2). Coadministration of low doses of benidipine $(3 \mu \mathrm{g} / \mathrm{kg})$ and diltiazem $(300 \mu \mathrm{g} / \mathrm{kg})$ almost completely inhibited the S-wave depression, where the efficacy was similar to that obtained with the use of high doses of benidipine $(10 \mu \mathrm{g} / \mathrm{kg})$ or diltiazem $(1000 \mu \mathrm{g} / \mathrm{kg})$ (Fig. 2).

Both benidipine $(3 \mu \mathrm{g} / \mathrm{kg})$ and diltiazem $(300 \mu \mathrm{g} / \mathrm{kg})$
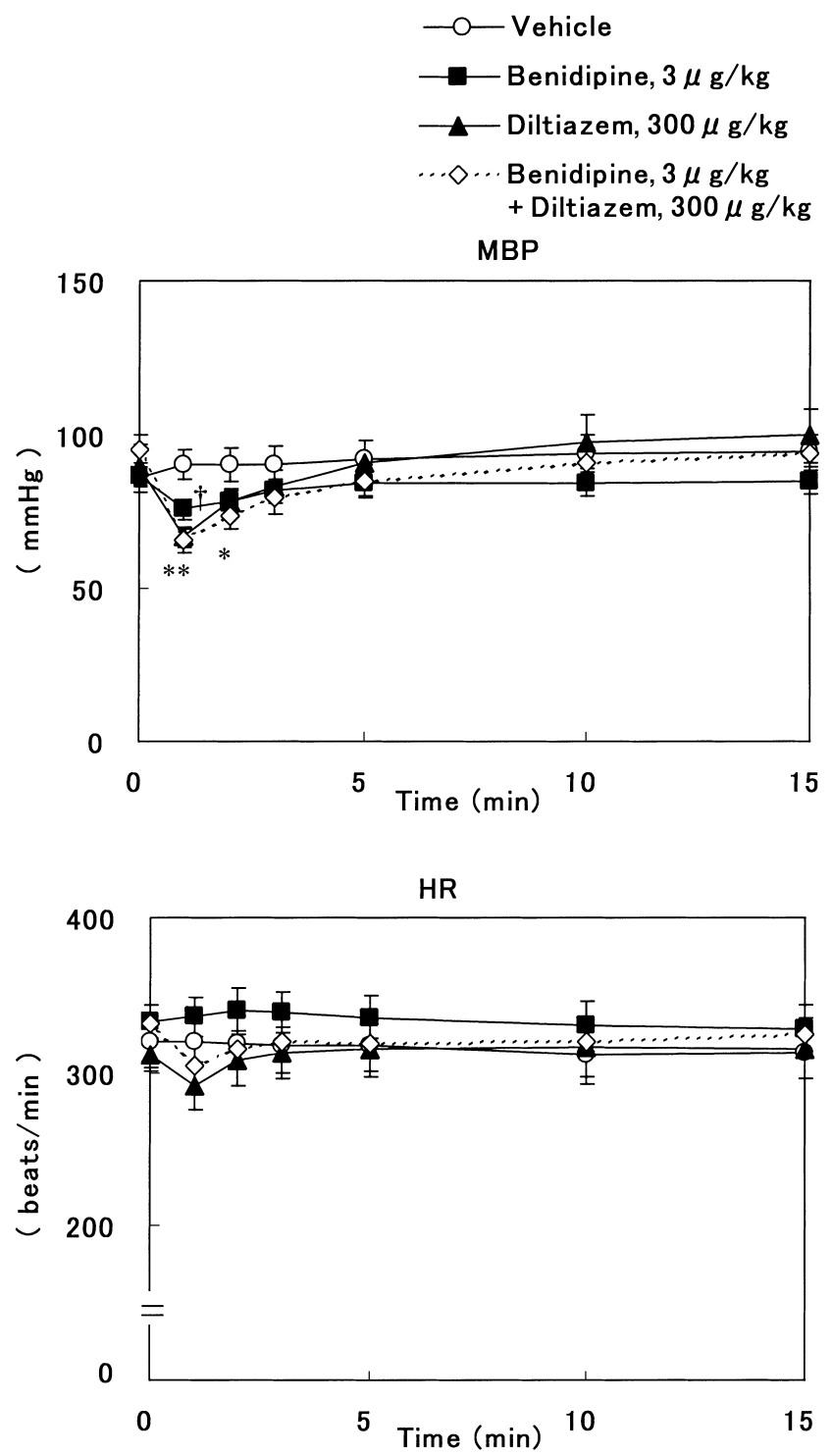

Fig. 3. Effects of the combination of benidipine and diltiazem on mean blood pressure (MBP) and heart rate (HR) in anesthetized rats. Data are means \pm S.E.M. of 5 rats. ${ }^{*} P<0.05$, ${ }^{*} P<00.01$ : vehicle $v s$ benidipine, $3 \mu \mathrm{g} / \mathrm{kg}+$ diltiazem, $300 \mu \mathrm{g} / \mathrm{kg}$. ${ }^{\dagger} P<0.05$ : vehicle $v s$ benidipine, $3 \mu \mathrm{g} / \mathrm{kg}$. decreased or slightly decreased blood pressure in normal anesthetized rats (Fig. 3). Co-administration of benidipine $(3 \mu \mathrm{g} / \mathrm{kg})$ and diltiazem $(300 \mu \mathrm{g} / \mathrm{kg})$ decreased blood pressure to the level of the diltiazem $(300 \mu \mathrm{g} / \mathrm{kg})$ group. Diltiazem $(300 \mu \mathrm{g} / \mathrm{kg})$ and coadministration of benidipine $(3 \mu \mathrm{g} / \mathrm{kg})$ and diltiazem $(300 \mu \mathrm{g} / \mathrm{kg})$ tended to decrease heart rate, whereas benidipine (3 $\mu \mathrm{g} / \mathrm{kg}$ ) did not affect heart rate (Fig. 3).

In general, calcium channel blockers possess vasodilating and negative inotropic effects. Consequently, their antianginal effects can be related to their ability to increase coronary blood flow (i.e., increase in myocardial oxygen supply) and/or to reduce myocardial oxygen consumption. Although they share common mechanisms of action, they differ in their affinity for the various tissues in the cardiovascular system. Therefore, the observed differences in pharmacological properties are based on their chemical structures.

Benidipine, a 1,4-dihydropyridine, is highly selective for vascular tissue and has fewer effects on nodal tissue in the heart (13). Consequently, it is reasonable to assume that the antianginal effects of benidipine are essentially mediated by its antispasmodic effect or the increase in coronary oxygen supply resulting from increased coronary blood flow. Diltiazem, a representative benzothiazepine derivative, also increases coronary blood flow. However, when diltiazem was administered intravenously, the effect was transient and recovery was rapid (14). On the other hand, diltiazem had a negative inotropic effect and decreased the heart rate. Therefore, reduced coronary oxygen consumption may partly contribute to the antianginal effects of diltiazem.

In this study, the combined use of diltiazem and benidipine produced additive antianginal effects compared to the use of each drug alone. Myocardial ischemia is typified by an imbalance between the supply and demand of myocardial oxygen. The effects of the combined drug administration were probably due to the sum of the decrease in myocardial oxygen demand and the increase in oxygen supply. In this study, the combined use of benidipine and diltiazem did not significantly augment the hypotensive effects of each drug in normal anesthetized rats. Combined effects of benidipine at $3 \mu \mathrm{g} / \mathrm{kg}$ and diltiazem at $300 \mu \mathrm{g} / \mathrm{kg}$ on heart rate were comparable to those of diltiazem at $300 \mu \mathrm{g} / \mathrm{kg}$, whereas the benidipine at $3 \mu \mathrm{g} / \mathrm{kg}$ had little effect on heart rate. Combination therapy of benidipine and diltiazem might possess favorable properties as a treatment for angina pectoris because benidipine has more potent coronary vasodilating activity than diltiazem, and diltiazem reduces myocardial oxygen demand more effectively than benidipine. The precise mechanism of the antianginal effects resulting from the 
combination strategy employed in the present study, however, remains unclear. In addition, it is important to examine the effects of the combination therapy in other animal models of myocardial ischemia (e.g., pacinginduced myocardial ischemia in the presence of significant coronary stenosis) in order to fully clarify the significance of this combination therapy in angina pectoris, and further investigations are necessary.

Diltiazem is widely used in the treatment of angina pectoris. However, its therapeutic utility has been limited by side effects such as bradycardia and atrioventricular (A-V) block (15). Quartaroli et al. demonstrated that diltiazem prolonged $\mathrm{A}-\mathrm{V}$ conduction and caused bradycardia and $\mathrm{A}-\mathrm{V}$ block at higher doses in dogs (14). In the present study, the co-administration of low doses of diltiazem $(300 \mu \mathrm{g} / \mathrm{kg})$ and benidipine ( $3 \mu \mathrm{g} / \mathrm{kg}$ ) almost completely inhibited depression of the S-wave, where the efficacy was similar to that obtained with the use of high doses of diltiazem $(1000 \mu \mathrm{g} / \mathrm{kg})$ or benidipine $(10 \mu \mathrm{g} / \mathrm{kg})$. These results suggest that employment of a combination approach using low doses of diltiazem and benidipine can yield an antianginal effect equivalent to that observed with the use of higher doses of either drug alone, with fewer undesirable side effects.

In conclusion, the present results indicate that the combination of diltiazem and benidipine exerts potent antianginal effects in the vasopressin-induced angina rat model, suggesting that employment of such an administration strategy may be useful in the treatment of angina pectoris.

\section{Acknowledgments}

The excellent technical assistance of Ms. M. Kobayashi is greatly appreciated. We thank Drs. K. Nagashima and A. Karasawa for valuable discussion about this study. We are grateful to Drs. H. Miki and M. Nakamura for encouragement and support.

\section{References}

1 Kitakaze M, Karasawa A, Kobayashi H, Tanaka H, Kuzuya T, Hori M. Benidipine: a new $\mathrm{Ca}^{2+}$ channel blocker with a cardioprotective effect. Cardiovasc Drug Rev. 1999;17:1-15.

2 Karasawa A, Kubo K, Shuto K, Oka T, Nakamizo N. Anti- anginal effects of the new calcium antagonist benidipine hydrochloride in anesthetized rats and spontaneously hypertensive rats. Electrocardiographic study. Arzneimittelforschung. 1988; 38:1702-1707.

3 Klein WW, Jackson G, Tavazzi L. Efficacy of monotherapy compared with combined antianginal drugs in the treatment of chronic stable angina pectoris: a meta-analysis. Coron Artery Dis. 2002;13:427-436.

4 Temkin LP. High-dose monotherapy and combination therapy with calcium channel blockers for angina. A comprehensive review of the literature. Am J Med. 1989;86:23-27.

5 Frishman W, Charlap S, Kimmel B, et al. Diltiazem, nifedipine, and their combination in patients with stable angina pectoris: effects on angina, exercise tolerance, and the ambulatory electrocardiographic ST segment. Circulation. 1988;77:774786.

6 Toyosaki N, Toyo-oka T, Natsume T, et al. Combination therapy with diltiazem and nifedipine in patients with effort angina pectoris. Circulation. 1988;77:1370-1375.

7 Hirata Y, Miyai H, Mabuchi Y, Aisaka K. Effect of JTV-506, a novel vasodilator, on experimental angina model in rats. J Cardiovasc Pharmacol. 1998;31:322-326.

8 Maturi MF, Martin SE, Markle D, et al. Coronary vasoconstriction induced by vasopressin. Production of myocardial ischemia in dogs by constriction of nondiseased small vessels. Circulation. 1991;83:2111-2121.

9 Satoh S, Ikegaki I, Toshima Y, Watanabe A, Asano T, Shimokawa H. Effects of Rho-kinase inhibitor on vasopressininduced chronic myocardial damage in rats. Life Sci. 2002; 72:103-112.

10 Yamamoto S, Matsui K, Sasabe M, Kitano M, Ohashi N. Effect of SMP-300, a new $\mathrm{Na}^{+} / \mathrm{H}^{+}$exchange inhibitor, on myocardial ischemia and experimental angina models in rats. Jpn J Pharmacol. 2000;84:196-205.

11 Mori T, Ishigai Y, Fukuzawa A, Chiba K, Shibano T. Pharmacological profile of semotiadil fumarate, a novel calcium antagonist, in rat experimental angina model. $\mathrm{Br} \mathrm{J}$ Pharmacol. 1995;116:1668-1672.

12 Rothman MT, Khan B. Coronary artery spasm. Br J Clin Prac. 1991;45:129-134.

13 Moriyama T, Karasawa A. Cardiovascular effects of benidipine and amlodipine in isolated tissues and anesthetized dogs. Biol Pharm Bull. 1994;17:1468-1471.

14 Quartaroli M, Gambini F, Tarter G, Micheli D, Trist DG, Gaviraghi G. The hemodynamic effects of lacidipine in anesthetized dogs: comparison with nitrendipine, amlodipine, verapamil, and diltiazem. J Cardiovasc Pharmacol. 1991;18: 326-336.

15 Haines DE, DiMarco JP. Sustained intraatrial reentrant tachycardia: clinical, electrocardiographic and electrophysiologic characteristics and long-term follow-up. J Am Coll Cardiol. 1990;15:1345-1354. 